\title{
La euritmia de Juan Emar: Teoría del equilibrio y sistema constructivo
}

\author{
Juan Emar's eurythmy: Equilibrium and constructive \\ system theory
}

\section{Cecilia Rubio Rubio}

Universidad de Concepción. Chile

crubio@udec.cl

\section{RESUMEN}

En este trabajo examino los conceptos desplegados por Juan Emar en sus escritos de carácter reflexivo de los años '20 (Cavilaciones (1919-1922) y los artículos sobre arte (1923-1927)), conceptos que conforman una red semántica sistemática que me permite proponer una lectura global de la obra emariana entendida como unidad de sentido. Esta conceptualización constituye una metafísica ocultista que se refiere a la relación sujeto-mundo como una relación cognoscitiva y constructivo-creativa de acuerdo a una poética eurítmica cuya base es una teoría del equilibrio regida por leyes numérico-geométricas. Sostengo aquí que hay evidencia del funcionamiento de este sistema constructivo en la práctica escritural emariana de los textos ficcionales de los años '30 (Ayer, Diez y Umbral).

Palabras claves: Literatura chilena, vanguardia y narrativa, Juan Emar, euritmia, teoría del equilibrio.

\section{ABSTRACT}

In this study I examine the concepts shown by Juan Emar in his reflexive-character writings from the '20s (Cavilaciones (1919-1922) and articles on art (1923-1927)). These concepts build up a systematic semantics net that allows to propose a global interpretation of Emar's work understood as a unit of sense. This conceptualisation is an occultist metaphysics that refers to the individual-world relationship as a cognitive and constructive-creative relationship according to eurythmic poetics, the base of which is a theory of equilibrium governed by numerical-geometrical laws. Here, I claim that there is evidence of this constructive system working in Emar's writing practice of fiction texts from the '30s (Ayer, Diez and Umbral).

Keywords: Chilean literature, vanguard and narrative, Juan Emar, eurythmy, equilibrium theory.

Recibido: 23-10-2008 Aceptado: 27-10-2008 
- $\mathrm{n}$ este trabajo propongo una lectura unitaria de la obra de Juan Emar, de Cacuerdo a la conceptualización sobre la realidad y el arte que Emar sostiene en los escritos de carácter reflexivo de los años '20 (el manuscrito Cavilaciones (19191922) ${ }^{1}$ y las notas sobre arte que publicó en el diario La Nación (1923-1927)). El análisis de estos escritos permite articular la concepción emariana del arte, cuya transposición como sistema constructivo se encuentra en la obra narrativa emariana de los años '30 (Ayer, Un año, Miltín 1934, Diez y Umbral'2).

En estos escritos reflexivos, tanto el arte como el ocultismo se presentan como dos modos análogos e idóneos de autoconocimiento y de conocimiento del mundo. Puede decirse que el sistema constructivo que rige la práctica ficcional emariana se presenta como una síntesis de la concepción del arte y del ocultismo. Esta concepción puede enunciarse como una poética del simbolismo hermético, según la cual se concibe la obra de arte como una euritmia de carácter pitagórico. Se trata de un complejo sistema, cuya base es una teoría del equilibrio que estructura la narrativa emariana de acuerdo a leyes numéricas y geométricas ${ }^{3}$.

\section{TEORÍA DEL EQUILIBRIO: LAS RAZONES MATEMÁTICAS DEL ARTE}

La concepción emariana de la vida y del arte constituye una metafísica que aparece regida en su totalidad por un concepto de la armonía que comprende aspectos cognoscitivos. Estos aspectos pueden comenzar a explorarse a partir

${ }^{1}$ Obra inédita, cuya única versión corresponde a la realizada por David Wallace como tesis de grado de Licenciatura en Humanidades por la Universidad de Chile en 1993.

${ }^{2}$ La novela Umbral fue publicada póstumamente en 1996, pero tengo datos de que su escritura habría comenzado a fines de los años '30. Pueden verse los diarios de vida inéditos de Juan Emar, que abarcan desde 1928 hasta 1941, donde se recogen menciones como la siguiente: "Sigo 2a de 'Ch 28 ' y llámolo 'Umbral'”(27 de noviembre de 1930). El 14 de abril de 1934 también registra su trabajo en "Umbral".

${ }^{3}$ En un trabajo anterior, complementario de éste, desarrollo la matriz pitagórica que rige el libro Diez. Remito, por lo tanto, al lector, a Rubio 2005. En líneas generales, el pitagorismo consiste en la concepción del universo como un cosmos, cuya ley de ordenación la constituye el número y la armonía o ritmo que de sus combinaciones matemáticas y geométricas resulta. En este sentido, el número sería un regente de un orden divino universal, en el que al macrocosmos se le atribuye el número diez y al microcosmos, el número cinco. En este sistema, entonces, la década representa el cosmos ordenado de acuerdo a la acción de la divinidad. Para la vida y filosofía de Pitágoras puede verse el libro octavo de Vida, doctrina y sentencias de filósofos ilustres, Tomo 2, de Diógenes Laercio, así como el análogo de Porfirio, Vida de Pitágoras. Para la filosofía pitagórica y, especialmente, la tetrakhtys, ver el importante libro de Paul Kucharski, Étude sur la doctrine pythagoricienne de la tétrade. 
del examen del concepto de conciencia, definido geométricamente como: “(...) punto en el infinito. Conciencia aquí es sinónimo de ese centro desde el cual florece la vida y desde el cual ella se aprecia" (1993: 222). Si a ello se agrega la idea de que "el yo es infinito" y se compone de capas ("cortezas") desde las cuales se participa en el mundo, a veces con "afinación total" entre ellas, otras, en desarmonía ${ }^{4}$, se comprende mejor que la conciencia es la extensión mínima que puede alcanzar el yo y, en tanto tal, adquiere el valor de un centro vital desde el cual se percibe el mundo. La consecuencia narratológica de esta concepción es el hecho de que la conciencia se presenta como el único centro de los relatos emarianos.

Por su parte, el concepto de "afinación" depende de una concepción mayor sobre la comprensión. Nótese la sinonimia creada entre "afinación” y "afinidad", entendida esta última como analogía, al mismo tiempo que como atracción o capacidad de concordar: "He llamado al hombre un receptor y al Universo un transmisor. Cuando hay afinidad entre ambos, hay comprensión. Un hombre debidamente desarrollado no irá recibiendo del Universo más que aquello con lo cual se afina. Y el progreso es normal. Pero la mayoría no procede así. Produciendo una desafinación contemplan el Universo" (Emar, 1993: 219). En efecto, el universo es concebido como una máquina de señales que el ser humano recepciona y dota de significados: "Existen estas afinidades en cualquier mundo. A cada instante estamos solicitados por ellas, mas son tan pocas las veces que nos detenemos ante estos sutiles llamados" (1993: 201).

La forma en que la percepción de las afinidades se vuelve un imperativo de investigación sobre la realidad se observa más adelante en el texto, de manera que la afinación/afinidad se incorpora a la concepción de la comprensión como modo cabal de conocimiento y de participación en la vida. Esta red conceptual se completará con los conceptos de equilibrio y unidad ("un total”):

Comprender lo entiendo en el sentido de poder crear ciertas relaciones y analogías entre lo que es objeto de observación y otros hechos o cosas, otros elementos en suma, de modo que lo observado no quede en aislamiento sino que pase a formar parte de un total equilibrio y que este total tenga además un equilibrio con la persona que observa, tenga, pues, una razón de ser. Así, ante todo un punto, una materia que se conoce; luego tejer los hilos que las unen a tantos puntos como haya necesidad para que todos unidos formen un concepto global por lo menos 'posible'. Que este total sea grande o pequeño, sea en su realidad verdadero o falso, ya es otra cuestión, con tal que por lo menos -repito- esté en armonía con la persona que observa, con su

“Parece claro que el concepto emariano de "afinación" equivale al significado que adquiere el término en la práctica musical, es decir, hacer concordar los instrumentos en cuanto al tono. 
temperamento, sus designios y la extensión que desee o pueda abarcar (Emar, 1993: 207-208).

En virtud de esta comprensión, se forma entre conciencia y mundo una figura que funciona como "construcción simbólica" y que se constituye en un sistema de equilibrios. El concepto de "construcción simbólica" lo extrapolo del cuento "El vicio del alcohol" y puede entenderse como un esquema de representación de carácter "absoluto humano" que aspira a ser un punto de convergencia de unidad y totalidad, y, en este sentido, a ser imitación de un absoluto suprahumano. Lo que Emar llamaba -consciente de su estatuto deficitario- "un absoluto humano" es un absoluto construido desde facultades humanas, pues si la condición de existencia de lo humano es la relatividad, se trata de una relatividad que aun estando en transformación continua, fija al mismo tiempo

la ley absoluta para 'cada caso', ley que pasa a ser relativa en otro caso (...). $\mathrm{Y}$ estas leyes forman como un manojo concéntrico, siendo las menores englobadas por mayores, las que a su vez se engloban y se ajustan a otras mayores que las comprenden hasta llegar así a la última o Absoluto en el sentido del Uno. (...)

En resumen: Todo es relativo y esta relatividad emana del Absoluto y es en cada caso y en todos ellos lo absoluto (1993: 229-230, 233, 234).

Más específicamente, el 'absoluto humano' es "la ley que rige la relación entre dos o más cosas". Por su parte, el modo de relación superior sería el que se logra por una "adaptación máxima a las leyes", las que son usadas "en la expresión más simple y pura que de ellas pueda hacerse o eliminando toda otra ley que no sea absolutamente necesaria para la creación de esa relación. (...) Las matemáticas, y la física y química teóricas realizan ese absoluto humano (...)" (Emar, 1993: 235). Posteriormente, Emar extiende esta facultad de producir absolutos humanos al arte, a todas las actividades humanas y a la naturaleza entera. En relación al arte, el modelo emariano son las matemáticas o, en sus palabras, las "matemáticas del arte", esto es, el modo perfecto de relación que podría ser "matemáticamente definido si tuviéramos el conocimiento exacto de las leyes de la sensibilidad humana" (1993: 236).

Esta búsqueda de realizar las "matemáticas del arte" es un objetivo artístico que se articula con la concepción eurítmica del arte. Veamos la nota "Cubismo", que Emar publica en el diario La Nación en 1923. Allí, Emar se refiere al aporte que hizo Paul Cézanne a la pintura al incorporar los conceptos de equilibrio y construcción. Para refrendar estos conceptos, Emar cita a algunos teóricos 
del Cubismo, como Maurice Raynal, quien compara la pintura cubista con la física moderna, ya que para ambas disciplinas lo que debe fijarse es una ley de las relaciones entre los elementos; y Leonce Rosenberg, para quien el Cubismo tiende a lo constante y a lo absoluto, pues desdeña lo particular y la anécdota. La última cita es la más extensa, completa y explícita en cuanto al aspecto que ahora reviso, la de Gino Severini, en la que éste parte definiendo el arte y la belleza como "el arte de la armonía". Para este autor, hay dos modos de realizar esta armonía, uno de los cuales consiste en la reconstrucción del universo "por la estética del número y por el espíritu”, modo de realización que caracterizaría el arte clásico. He aquí las conclusiones de Severini:

\section{'(...)}

La obra de arte debe ser Eurítmica; es decir que cada uno de sus elementos debe estar ligado al todo por una relación constante que satisfaga ciertas leyes.

Esta armonía viviente podría llamarse: equilibrio de relaciones, pues así el equilibrio no es como hoy día se comprende: un resultado de igualdades o de simetrías, sino que resulta de una relación de números o de proporciones geométricas que constituyen una simetría por equivalentes.

Esta estética está de acuerdo con las leyes con que nuestro espíritu ha comprendido y explicado el universo desde Pitágoras y Platón. Por ello, sabemos que todo en la creación es rítmico según las leyes del número, y gracias a estas leyes únicamente, nos es permitido volver a crear, reconstruir equivalentes del equilibrio y de la armonía universales.

El fin de las artes puede ser definido así: reconstruir el universo según las mismas leyes que lo rigen' (Cit. por Emar, 2003: 55).

Es cierto que no es difícil verse inducido por esta cita a pensar, como Varetto, que Emar habría intentado "dar forma en la prosa, (...) narrativizar quizá, la teoría cubista de la obra de arte" (Varetto, 1993: 37). En este sentido, se puede observar que en la nota de arte del 16 de julio de 1924, titulada "Moi, je pense", Emar se refiere a la literatura en términos parecidos a los usados por los teóricos del Cubismo para referirse a la pintura, al señalar que la literatura es "un arte de las palabras" que debe regirse por sus propias leyes, las que consisten en una "justa proporción, justa construcción" (2003: 121), por lo que el escritor se doblega a un ideal de medida, de proporción y de ritmo. Posteriormente, en la nota del 6 de agosto de 1924, "Al arte lo que es del arte", Emar reclama que el arte sea juzgado como se juzga una obra científica, por su "serenidad y exactitud", pues, alega, éstas son las "razones del arte" (2003: 127). 


\section{SISTEMA CONSTRUCTIVO Y LEY DEL NÚMERO: EL SEGUNDO, EL TERCERO Y EL CUARTO PERSONAJE}

El carácter metapoético de estas ideas se comprueba en el análisis de los textos emarianos de ficción. En efecto, la teoría del equilibrio es notoria en la novela Ayer, donde se presenta a través de la subteoría de los colores formulada por el pintor Rubén de Loa:

Pues el rojo, al ser complementario del verde, en cualquier circunstancia de la vida, lo complementa. (...) Quien complementa, equilibra; quien equilibra, hace estable (...) quien hace estable, hace viable. (...) Hace viable la circulación de la vida a través. (...) La vida circula a través, puede circular, gracias a que tiene por donde circular. Esto es elemental. Y lo tiene, gracias a que hay, en aquello por donde circula, una estabilidad, y esta estabilidad es únicamente posible, gracias a un equilibrio constante, o casi constante, y para que haya equilibrio tiene que haber por lo menos dos que se equilibren (Emar, 1998: 34-35) .

Si retenemos las premisas de esta teoría, podemos sintetizarla como sigue: en el mundo las cosas se equilibran entre sí de manera (relativamente) estable, de allí que haya que considerarlas en su unidad como una configuración: el uno es siempre dos que están en tensión. Esta tensión confiere a la figura un movimiento vital, el de circulación. Es en virtud de esta rotación constante que la vida se hace posible ("viable"), de este modo, la figura se transforma en un pequeño organismo que se estructura con estos dos puntos interconectados en el tiempo y en el espacio.

En primera instancia, la teoría del equilibrio afecta directamente el mundo narrado en el plano del número de personajes. La explicitación sobre este asunto se encuentra en la introducción a Umbral, "Palabras a Guni", donde el narrador explica su necesidad de poner en acción a dos personajes, para cumplir con la ley ya no sólo del uno que deviene dos, sino que también con la de polarización, ya que se requiere ahora que los personajes actúen como fuerzas separadas que se polarizan. De esta manera, el segundo personaje, o el desdoblamiento de uno solo, es una categoría marcada que funciona como uno de los recursos para polarizar el relato.

Así, en Umbral, el narrador Onofre Borneo se desdobla en el narrador parcial Lorenzo Angol, quien, a su vez, queriendo desdoblarse en uno que actúa y otro que contempla, solicita a Borneo le construya un segundo personaje que cumpla este segundo papel, para lo cual Borneo hace intervenir a Rosendo Paine, quien se ofrece para actuar como doble de Angol. Veamos cómo lo explica Borneo: 
Es como un contrato. Es abarcar entre dos el total ya que uno solo no lo ha logrado. Es ocupar ambos polos, el positivo y el negativo, el blanco y el negro, como quiera usted llamarlos (Emar, 1996: 7).

Veamos también lo que sucede en un pasaje de "Maldito gato", donde la polarización aparece como una forma de afinidad:

Pues al fin y al cabo un rayo, uno solo, como lo digo, "uno", es una unidad y hasta ahora, que yo sepa, en la unidad uno, no ha sido posible realizar expresión alguna de vida manifestada, ni recibir eco de ella, ni generar propulsión, ni guardar equilibrio de la misma. (...)

¡Ah! ¡Pero aquí viene el papel de la pulga! Y ya, haciendo entrar a dicha pulga en nuestro sistema, iremos formando una figura organizada que, por el hecho de ser figura, y no más una unidad una -que como tal tendría que ser infigurada-, puede ya pasar a ser o pasar a tener una relación, una conexión, una afinidad, una polarización, si se quiere, con todo el resto de lo creado, con la otra y total figura (Emar, 1997: 50).

La noción de 'polarización puede ayudarnos a situar en la escena los elementos y explorar las consecuencias que de allí resultan. Si para el personaje la figura que allí se recortaba es la "polarización de la vida concentrada en un punto", puede verse cómo la cuestión del desapego o de la no funcionalidad de los sentidos ni su antecedente desapego a la sensación térmica constituyen a su vez una experimentación con la polarización. La actitud de búsqueda de un punto de concentración y condensación en el propio yo permite aprehender lo vital en su sentido elemental, básico. Dicha actitud se distingue por la afirmación de la permanencia de un sentido único (la vista) que se presenta como síntesis de unidad y diversidad, es decir, como imagen de totalidad.

Esta búsqueda de la síntesis recuerda inevitablemente la obsesión condensatoria manifestada en "El pájaro verde" en la satisfacción por la fórmula encontrada de "yo he visto un pájaro verde". ¿Se trata de un signo de austeridad o de reduccionismo? No es fácil precisar las motivaciones de tal actitud, pero sí prever o proyectar sus alcances. Si se logra determinar el punto específico en el que reside lo vital, la austeridad es cosa probada. La vida se concentra en 'ver' una vez que ha operado la reducción de los sentidos, ¿`cómo, entonces, sacar de allí 'un' sentido? Por un lado, la superación de toda necesidad constituye a la persona en una manifestación de libertad. Por otro lado, necesariamente si la vida se polariza en un punto ha de establecerse un polo de contraste, vale decir, la reducción no puede operar sólo en la persona, sino que es imprescindible que ésta se produzca también en la vida de 'lo demás'.

La dualidad que configura el tema emariano del doble no sólo da origen a 
la complicidad, como ocurre entre los 'segundos personajes' por excelencia de Diez: Desiderio Longotoma, "el cínico de Valdepinos" y "el violinista distinguido Julián Ocoa", sino a la lucha mortal, como sucede en "El unicornio", entre una parte del ser del protagonista que quiere ser pasivo e irresponsable y, la otra, la parte asesina que quiere ser activa y culpable. El otro caso paradigmático es el más complejo de "El pájaro verde", pues el tío José Pedro actúa como tercer personaje, desde el punto de vista de la totalidad de la figura, pero como segundo respecto de la dualidad enemiga que establece con el loro, de allí que éste lo ataque y lo destruya definitivamente. Lo que ocurre en este cuento puede explicarse de un modo que resalte la función constructiva de la fórmula encontrada, cuestión que es inherente al combate entre las fuerzas del tío José Pedro y del loro. En efecto, cuando el desequilibrio se produce por una incompatibilidad tal que escapa a toda posibilidad de complementación, nos encontramos en el dominio de la polaridad en estricto sentido. Por ello, son estas mismas fuerzas las que se rechazan y se atraen para destruirse la una a la otra. En la escena del ataque del loro al tío José Pedro, lo que hace el pájaro al interpelar al protagonista es derivar su posibilidad de intervenir como fuerza actuante a favor del tío hacia una intervención mediatizada socialmente (fórmula de saludo exige respuesta) que anula la fuerza solidaria del protagonista, con lo cual el loro impide a éste entrar como tercer elemento en una lucha de dos. Si el combate es mortal, ello se debe a esta neutralización (social-formulística) de quien se había proyectado como fuerza interventora. Este factor o fuerza de neutralización se instala como presencia actuante entre el protagonista y el loro, llevando al personaje al cambio de conducta denunciado por éste al final del relato, el que puede sintetizarse como una neutralidad emocional que lo destina a ser para siempre un sujeto contemplador (y contemplativo), es decir, lo que lo instala para siempre en el modo de ser de la inacción ${ }^{5}$.

Como se observa, en el sistema emariano dos no son suficientes para que haya vida, pues la polarización instaura a su manera un nuevo desequilibrio, ya que se desata la fuerza destructiva que hace a los factores aniquilarse mutuamente. Se necesita, entonces, un tercer personaje. Nuevamente encontramos en Umbral la explicitación teórica, en palabras de Borneo:

(...) presumo la existencia de un tercer personaje -déjeme llamarlo así con mayúsculas: Tercer Personaje-, personaje recóndito, muy oculto en un arcano fuera de toda visión y de toda comprensión humanas: el personaje que, sosegada e inexorablemente, advierte que el encuentro entre dos de la unidad

${ }^{5}$ Cabe hacer notar que el cotexto de "El pájaro verde" en la versión de Umbral tiene como uno de sus temas el camino de la inacción. 
no es cosa hacedera en este mundo. Lorenzo y Rosendo chocan. Lorenzo y Rosendo son los dos amigos atraídos por la colaboración entusiasta y sincera. Ellos son los hombres que, por senderos muy tortuosos, hallarán siempre un impedimento o una burla a ese intento equivocado. Grandes amigos que todo lo ensayan, que ante ningún experimento se arredran y que se destruyen. La cuerda se rompe y se separan (Emar, 1996: 8).

Emar avanza, entonces, de la dualidad a la trinidad, lo que equivale a avanzar en el plano geométrico desde el paralelo o desde el ángulo al triángulo, al establecer los requisitos del equilibrio como la formación de una figura compuesta por tres entidades que son tres "fuerzas" del equilibrio cósmico, como ocurre en "Maldito gato". Pero, en el caso de este cuento, no sólo se trata de construir una figura donde las fuerzas se equilibren, sino de que dicha figura encierre en sí una forma de existencia que pueda constituirse en paralelo del cosmos, es decir que sea ella misma unidad y totalidad. En este sentido, y como puede extrapolarse a otros textos, la totalidad posee su propia fuerza contextualcósmica que actúa de distinta manera, según se enfrente a ella misma como totalidad o según se refiera a las partes que la componen en tanto unidades relativas. Por lo demás, la tétrada pitagórica que rige en Diez no sería tal sino se conformara de cuatro entidades, cada una de las cuales es una en sí misma y en sí misma absoluta, a la vez que un todo relativo respecto del Todo.

No es extraño, entonces, que una de las consecuencias de la presencia de una fuerza contextual sea el nacimiento del cuarto personaje, funcional y relativo como ningún otro en relación al conjunto, pero omnipresente como totalidad o como sentido. Evocado a menudo in absentia, el cuarto principio actúa desde el todo rearticulando y haciendo nuevamente relativas las presencias de los otros tres. Si el cuatro es el número de la totalidad en la tétrada pitagórica y en la emariana de Diez, es también el número más esotérico y más arcano de todos, el que en Diez ocupa el lugar de lo imaginado e inexistente, el unicornio; y el que no se expresa en cifras y como tal no es contado en la operación matemática que hace el narrador de "Maldito gato", que insiste en nombrar la trilogía, pero reservando para el cuatro de la totalidad el único nombre del "otro" 6 .

${ }^{6}$ Para el pitagorismo, el cuatro es también el número de Dios, ya que es la unidad Uno por excelencia (la Mónada), que es a la vez una trinidad: principio masculino y principio femenino que en su unión perfecta generan el cosmos. El número siete, entonces, es la unión de Dios, que es cuatro, con el cosmos, que es tres: cielo, tierra y humanidad. Dios es uno y todo, "el Número de los números", es decir, la causa primera y única. 


\section{DEL TRIÁNGULO AL CÍRCULO: UNIDAD Y TOTALIDAD}

El recorrido seguido hasta aquí se completa con otros elementos del sistema emariano, uno de cuyos contenidos no sólo se refiere a la euritmia como imagen en movimiento articulado, sino que eleva a ésta a imagen sintética del cosmos en un esfuerzo que la equipara a la euritmia representada en la tétrada de Pitágoras. Esta construcción sintética está relacionada con los conceptos de unidad y totalidad.

La búsqueda de totalidad que emprendió Emar está bastante bien documentada. Basándose particularmente en "Torcuato", Umbral y Cartas a Carmen, respectivamente, Brodsky ([1994?]), Piña (1998) y Lizama (2000) aluden a ella de una manera similar. Tanto Brodsky como Piña refieren el concepto de totalidad al de afán escritural de carácter autobiográfico totalizante. En la misma perspectiva, pero señalando los alcances narratológicos, Lizama sostiene que la obra emariana está marcada por un anhelo de reconstrucción de la vida propia y de todas las vidas, anhelo que tiene su expresión en el hecho de que el narrador emariano multiplique los detalles y expanda infinitamente las descripciones, de forma que el discurso narrativo se hace multidireccional y termina por revelar el mundo entero.

En otro de sus trabajos, Lizama (2001) plantea de nuevo el tema de la totalidad, extendiendo su alcance a una percepción orgánica y holística de la vida. Específicamente, Lizama propone que al concebirse el mundo como una unidad tanto indivisible como dinámica, "los componentes del universo, desde el nivel macrofísico al microfísico, no son 'cosas', sino correlaciones de cosas que, a su vez, son correlaciones de otras cosas y así sucesivamente" (2001: 29). En síntesis, el universo es un conjunto unificado de una red compleja de relaciones entre sus diferentes partes. El narrador emariano se hace cargo de esta complejidad, de allí que no pueda dejar de seguir esta red de relaciones.

Contamos también con una explicitación en un texto ficcional emariano, donde este rasgo aparece como un designio narrativo de abarcabilidad de la unidad entendida como totalidad. En este sentido, se trata de un aspecto inherente al hecho de narrar, tal como se le presentaba a Emar. Me refiero al texto "Oye", incorporado en Umbral, Segundo Pilar, "El canto del chiquillo", donde se lee lo siguiente:

Tendré que hacer un verdadero esfuerzo para mantenerme ahora sobre una misma línea, una línea recta en lo posible, recta cuanto se pueda a lo largo de este relato. Verdadero esfuerzo para no escaparme a derecha o izquierda. Porque la esencia misma del relato es la escapada permanente hacia todos lados, todos los puntos, todo lo que es. Y la voluntad mía: reunir cuantas 
escapadas haya sobre una línea de continuidad lógica y -¡ojalá!- dentro de un solo globo que todo lo encierre en unidad (1996: 1130).

La idea del globo aparecerá con características similares en Miltín 1934, lo que Brodsky ([1994?]) vincula a la visión de lo absoluto llamada satori en el budismo zen. Por su parte, la cadena interminable de relaciones posibles de narrar se encuentra también en la novela Ayer, cuando el narrador protagonista se propone aprehender la entidad "gordo". En dicho intento, su pensamiento caerá de pronto en la pelusa del pantalón y de allí pasará al bolsillo, de éste al chaleco, de éste a la panza y de ésta, de nuevo, al gordo. El protagonista dice perderse en el todo, todo en relación al cual "el gordo no es" (1998: 53):

El panzón agarrado a este aire polvoriento que se agarra de los muros, que se agarran del edificio entero. Edificio que puede existir únicamente porque hay donde existir y lo hay porque rueda la Tierra junto al sol, porque el sol es respecto a las constelaciones que son porque son respecto al cosmos, que es ... (sic. 1998: 52).

Pero la idea del globo tiene otras formas de expresión. Por su planteamiento de sentido, hay que recurrir una vez más a "Maldito gato". En última instancia, la figura que se forma por medio de tres factores se resuelve en el círculo. Si de imitar el mundo se trata, la figura debe incorporar un mecanismo que lo haga vibrar, de allí la idea de la circulación que completa la figura en tanto "construcción simbólica" del todo, en una dinamia que se asemeja a la vida. Así lo percibe el pintor de Ayer, como ya he citado ("La vida circula a través, puede circular, gracias a que tiene por donde circular"), y el protagonista de "Maldito gato": "ya entonces pudo la vida, no sólo llegar, no sólo pasar, sino que circular, circular así: yo, él, ella; él, ella, yo; ella, yo, él... circular, circular siempre, circular definitivamente, al lado, al espejo de la otra" (Emar, 1997: 52).

Por esta vía, lo que el arte produce son construcciones simbólicas del todo, obras orgánicas en que se juega el destino de unos seres que se mueven en lo absoluto de los signos y los sentidos en tanto componentes de un mundo paralelo a la "otra vida". De dotar el mundo de signos y de sentidos trata la búsqueda por aprehender los objetos mínimos, visibles o no, condensación de lo abstracto inaprehensible: una frase en "El pájaro verde", tres puntos en "Maldito gato", un caracol sobre una tumba en "El perro amaestrado", una estatua en "El unicornio", un anillo en "Papusa", un cuadro en "Chuchezuma", unos zapatos en "Pibesa", un sueño en "El hotel Mac Quice", una noche en "El fundo de La Cantera", un grito en "El vicio del alcohol". Se comprenderá, entonces, por qué la obra emariana está regida por la metonimia y la sinécdoque más que 
por la metáfora o la analogía. Digamos más claramente que si el pensamiento del narrador emariano se estructura como un pensamiento profundamente analógico, que establece relaciones entre objetos, sensaciones e ideas, es por la contigüidad que estas relaciones se van a expresar, de manera que las dos entidades unidas por asociación, al hacerse continuas en el pensamiento y en el discurso, se cristalizarán en un solo objeto que las unifica ${ }^{7}$.

Esta intención sobrecodificadora se expresa magistralmente en la "construcción simbólica", entendida como voluntad, como actitud y gesto, y como objeto concreto. En líneas generales, se trata de combatir, de corregir el absurdo del mundo a través de la proposición de otros esquemas posibles que lo organicen, dando lugar en ellos a los deseos y sustentando por el equilibrio las fuerzas que así se unificarán. La "construcción simbólica" se crea en cada uno de los cuentos y resuelve los conflictos en la medida que sólo ella permanece como última afirmación vital-artística.

\section{CONSTRUCCIÓN Y SINSENTIDO: EL LEITMOTIV DE LA FUGA}

Para completar esta visión unitaria del sistema emariano, es necesario recurrir ahora al momento en que el pintor Rubén de Loa, de la novela Ayer, explicita el carácter posible y proyectivamente informe de una obra construida según la teoría del equilibrio, si al cambiar las condiciones de ese cuarto factor innombrado que es la totalidad, uno de los elementos cae en el vacío. El vacío es un aspecto del plano físico de la figura, pero en un plano contextual-metafísico, el vacío es el sinsentido:

(...) Pero ello no quita que parte de los rojos al ser sacados de aquí, quede ociosa. Tú dirás, pequeña parte; yo, gran parte. Como sea, estamos de acuerdo con la existencia de esa parte. Y esa parte ociosa, colgadas ya las telas en un muro de exposición, empezará a buscar un objetivo, a rondar, a tratar de emplearse, a mortificar a cuantos ojos se posen sobre ella, a crear el yerro, a implantar el malentendido, a tender un velo de desconcierto entre los espectadores y las doce telas. $\mathrm{Y}$ va a resultar, mi buen amigo, que nadie va a entender palabra y que todos van a salir de allí con una engorrosa sensación de sinsentido (1998: 79).

${ }^{7} \mathrm{Al}$ contrario del procedimiento que, según Genette (1972), caracteriza la escritura de Proust, es decir, el de presentar analogías y metáforas en las que subyace una metonimia, en la obra de Emar encontramos metonimias y sinécdoques en las que subyacen analogías y metáforas. Ver "Métonymie chez Proust", en Figures III. 
En la cita se expresa también un factor que hasta ahora sólo he mostrado parcialmente: el factor del "desparramo", como dice frecuentemente el personaje emariano -lo que llamo el leitmotiv de la fuga, cuya mejor actualización se encuentra en "El fundo de La Cantera". Este factor se explica al concebir la figura como un sistema orgánico y dinámico, donde las partes no se relacionan con el todo de manera unívoca, lo que transforma la configuración en una totalidad distinta. Cualquiera sea la forma en que ésta cambie, ya sea por articulaciones distintas de los factores y fuerzas, ya sea porque algo ha cambiado en el todo, esto produce un desequilibrio, cuya máxima expresión es la fuga del elemento que ha quedado "ocioso" o de otros factores que aparecen para ocupar momentáneamente el lugar de aquél.

No podría ser de otra manera, si consideramos el carácter humano de la construcción simbólica y su sostenimiento en la conciencia y la voluntad -humana o suprahumana, pero siempre 'viva'. Es la presencia de esta voluntad la que determina que el sistema emariano sea altamente entrópico, pues lo humano y lo vivo son de por sí impredecibles?

Pero lo justo es integrar una posible concepción del Todo-Dios como demiurgo que ha descuidado algunos aspectos del equilibrio cósmico. Veamos la única versión de esta idea, que da luces, no obstante, sobre su operación en el sistema. Proviene de "Maldito gato":

Tres fuerzas así, así, largas, larguísimas; en el espacio tan largas que, ya habiéndolo surcado todo, habían perdido sus formas iniciales de serpientes largas que se estiran y ya, sin formas, tenían la forma de ser y nada más; y en el tiempo tan remotas, tanto, que no podían tener como origen más que tres míseros, infinitamente míseros, gestos descuidados del Todopoderoso, Omnipresente y Omnisapiente cuando vínole a Su voluntad crear un mundo -creía Él- de exactos equilibrios (1997: 53).

Por lo demás, esta cita podría explicar también el origen de la "construcción simbólica" por la necesidad de corregir estos gestos descuidados de Dios en la conformación del universo. En cualquier caso, las referencias y especulaciones del personaje sobre la posibilidad de regresar a un caos cósmico a partir de la

${ }^{8}$ Adriana Castillo (1992) se refiere al uso de un mecanismo de la fuga en el cuento "Chuchezuma" y reconoce que el narrador es la única instancia fija del cuento.

${ }^{9}$ En términos generales, la entropía puede definirse como un principio de desorden inserto en los sistemas. Por su parte, el atributo de "impredecible" en este contexto, está ligado a la teoría del caos, según la cual dado un sistema determinista, los resultados de su realización adquieren formas impredecibles. Cabe hacer notar que la realidad de la entropía estaría inscrita implícitamente en el pitagorismo, como explica el estudioso de las matemáticas Miguel Parra León (1966). 
destrucción de este precario equilibrio creado como una totalidad se vinculan con el leitmotiv de la fuga y la entropía del sistema-figura. En efecto, una vez trazadas las dos primeras líneas que van de los ojos de la pulga a los del gato, y de éstos a los del protagonista, este último señala que por esas líneas pasan las vidas de los tres seres, pero luego se cuestiona y corrige:

¿Pasan? ¡Aún no! Porque, de pasar por ellas se irían, se irían para siempre, se desvanecerían en el infinito, pues la figura no ha sido cerrada todavía y, al no haberlo sido, deja en cada uno de sus extremos dos puertas, dos bocas abiertas hacia la infinitamente nada. Y la vida hay que cerrarla, encerrarla, limitarla, dibujarla. De lo contrario, el mundo todo, el cosmos, convergería precipitándose hacia el imán de estas dos líneas, y una mitad se pulverizaría de la pulga para allá y de la otra de mi punto para acá. Y nada subsistiría en nada (1997: 52).

No obstante esta apremiante necesidad de cerrar la figura-sistema, verificable también en el final de la novela Ayer, Emar parece estar de acuerdo con Borges, cuando éste prevé la muerte del universo en la posibilidad de nivelación o compensación de la energía, a lo que llama "mortal equilibrio" (cf. "La doctrina de los ciclos"), pues si bien para Emar es el equilibrio el único garante de la estabilidad de lo vital, no deja de tener algo de "mortal", como lo prueba la tendencia al estatismo observable en los finales de los cuentos de las secciones "Cuatro animales", "Tres mujeres" y "Un vicio", donde el personaje logra llegar a una entropía cero, gracias a la "construcción simbólica". La excepción la constituyen los cuentos de la sección restante, "Dos sitios". Pero esto no es del todo exacto. Todavía están subiendo las putrefacciones de Emar por la estatua de Camila ("El unicornio"), todavía chorrean sangre los taconcitos de Pibesa ("Pibesa"), todavía avanza sobre la tumba de Piticuti un caracol ("El perro amaestrado").

\section{REFERENCIAS}

Borges, Jorge Luis. 1974. Obras Completas. Buenos Aires: Emecé. Brodsky, Pablo, comp. [1994?]. Juan Emar. Antología esencial. Santiago: Dolmen. Castillo, Adriana. 1992. "Texto e intertexto en 'Chuchezuma de Juan Emar". Revista Chilena de Literatura 40, pp.123-128.

Diógenes Laercio. 1965. Vie, doctrine et sentences des philosophes illustres. Tome II. Traducción, noticia y notas de Robert Genaille. Paris: Garnier Frères.

Emar, Juan. 1993. Cavilaciones, en Wallace, David. "Cavilaciones de Juan Emar".

Tesis de Licenciatura en Humanidades. Universidad de Chile, Santiago. 
1996. Umbral. 5 vols. Santiago: Biblioteca Nacional.

1997. [1937] Diez. Santiago: Universitaria, 2a ed.

1998. [1935] Ayer. Santiago: Lom.

2003. Notas de Arte (Jean Emar en La Nación: 1923-1927). Edición de

Patricio Lizama. Santiago: Ril editores; Centro de Investigaciones Diego Barros Arana.

Diarios, ms. Fundación Juan Emar. Santiago.

Genette, Gérard. 1972. Figures III. Paris: Éditions du Seuil.

Lizama, Patricio. 2000. "Cartas a Carmen (Correspondencia entre Juan Emar y Carmen Yáñez, 1957-1963)”. Inti. Revista de Literatura Hispánica 51 (primavera): 153-158. pp. 25-33.

2001. "Emar y el deseo de otra esencia para la vida". Paréntesis 8 (marzo),

Parra León, Miguel. 1966. Pitágoras. Fundador de las ciencias matemáticas. Caracas: Arte.

Piña, Carlos. 1998. "El delirio biográfico de Juan Emar". Taller de Letras 26, pp. $143-47$.

Porfirio. 1987. Vida de Pitágoras. Argonáuticas órficas. Himnos órficos. Introducciones, traducciones y notas de Miguel Periago Lorente. Madrid: Gredos.

Rubio, Cecilia. 2005. "Diez de Juan Emar y la tétrada pitagórica. Iniciación al simbolismo hermético”. Taller de Letras 35, pp. 149-166.

Varetto, Patricio. 1993. "Emar, la tradición literaria y los otros a través de "Un Año", en revista Pluma y Pincel 165, pp. 36-37. 